\title{
STUDIES WITH INAGGLUTINABLE ERYTHROCYTE COUNTS. IV. GRAPHIC ANALYSES OF RATES OF PRODUCTION AND DESTRUCTION OF HUMAN ERYTHROCYTES ${ }^{1}$
}

\author{
By ELMER L. DeGOWIN, JASON A. ELLIS, RAYMOND F. SHEETS, \\ HENRY E. HAMILTON, AND CLINTON D. JANNEY
}

(From the Departments of Internal Medicine and Physiology, and the Radiation Research Laboratory, State University of Iowa, Iowa City, Iowa)

(Submitted for publication April 16, 1953; accepted October 7, 1953)

Many diseases have been studied by transfusing patients with normal red cells of heterologous blood group and the identification and enumeration of the donor's cells in the circulation of the subject by the differential agglutination method of Ashby. In certain of such experiments the assumption may be made, or the fact proven by cross transfusion, that the transfused cells are destroyed in the same manner and at the same rate as the subject's own. DeGowin, Sheets, and Hamilton (1) were the first to demonstrate that once the rate of disappearance of the biologically tagged cells is determined by adequate counts, contemporaneous enumerations of the subject's own cells can be employed with certain assumptions to calculate the rate of cell release. Thus the patterns of both production and destruction of red cells may be studied in man by the transfusion technique. Thorough exploitation of the possibilities of this quantitative method promises further insight into the mechanisms of many diseases of the blood.

In normal human beings a state of equilibrium is maintained by the production and destruction of erythrocytes at equal rates. The resulting concentration of erythrocytes in the circulation remains, therefore, approximately constant, barring temporary shifts in plasma volume and the loss of blood during menstruation. This constitutes the normal steady state. In certain diseases, however, steady states are maintained for many months during which the erythrocyte levels in the circulation are higher or lower than normal. Theoretically these abnormal steady states can occur in several ways. The state of oligocythemia apparently does occur either with a normal numerical rate of pro-

\footnotetext{
1 This investigation was supported in part by the Medical Research and Development Board, Office of the Surgeon General, Department of the Army, Under Contract No. DA-49-007-MD-485.
}

duction of cells and an increased rate of destruction, or with a normal rate of loss and a diminished rate of numerical production. Polycythemia results from an increased rate of numerical production and a normal or a disproportionately diminished rate of destruction.

Consideration of the facts in pernicious anemia, however, bring the realization that the foregoing statements contain the assumption that erythrocytes appear in the peripheral circulation at the same rate that they are numerically produced in the bone marrow.

The present studies focus attention on another phenomenon which we shall term the rate of $n u$ merical release of erythrocytes from the bone marrow, henceforth shortened to rate of cell release. By this is meant the number of erythrocytes released to the peripheral circulation from the bone marrow in unit time. This rate may or may not coincide with the numerical rate of erythrogenesis but it is the process which can be measured by the methods employed in these studies.

In this paper we present graphic methods for analyzing the data obtained in transfusion experiments by the technique of differential agglutination. The discussion is so organized that the text relating to the graphic presentation and the argument involving simple algebraic manipulations is printed in the usual sized type, whereas the strict mathematical proofs employing calculus are presented in fine print and may be passed over at the option of the reader.

Previously (2) it was shown that in many cases the loss of erythrocytes from the circulation occurs either solely by senescence or by aging plus random destruction. Here we will consider primarily the effect of random destruction on the equilibrium between rate of cell release and loss of cells in four situations: the normal steady state, 


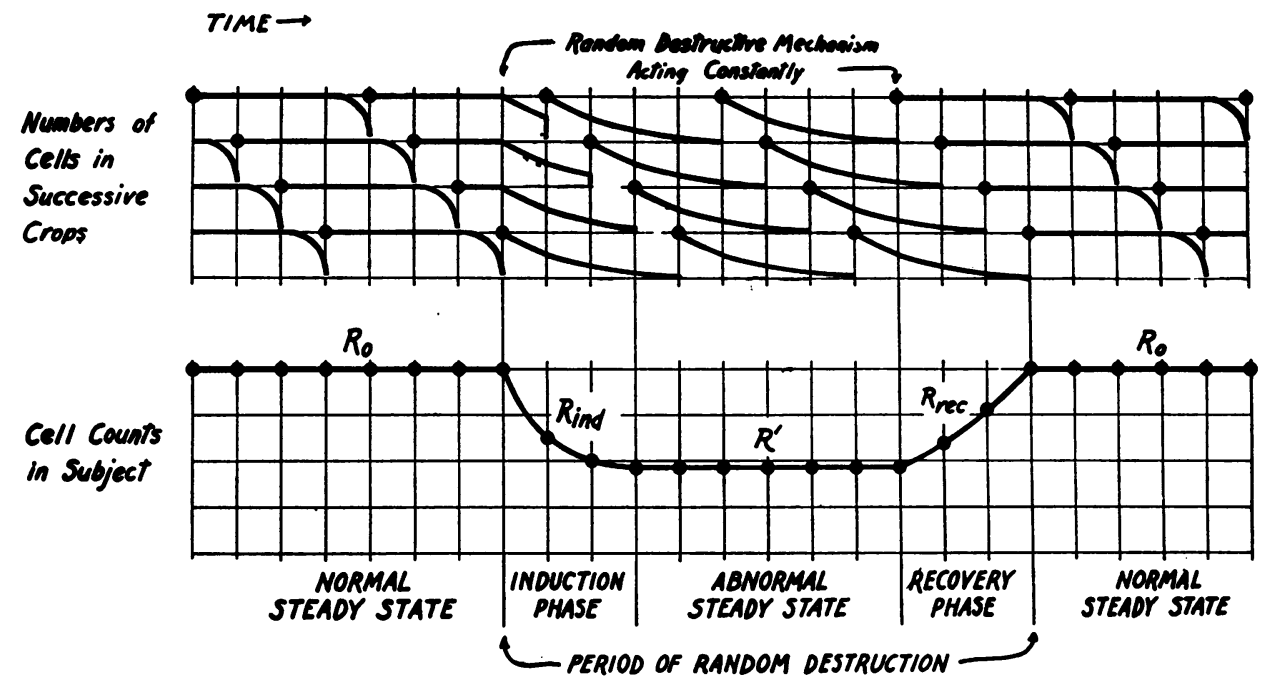

\section{Rate of Erythropoiesis}

Constont Throughout

Fig. 1. Changes in the Erythrocyte Level Effected by a Hypothetical Random Destructive Mechanism Resulting in an Abnormal Steady State

Cell counts are plotted on the vertical axis of Cartesian coordinates against time units on the horizontal axis. The rate of cell release is stipulated to be normal throughout. The sum of the cell counts of all contemporaneous crops at any time $t$ equals the erythrocyte count of the subject. The assumptions are made that the random destructive mechanism removes successive crops of erythrocytes in the same manner and that, once the cells are injured, they continue to be lost at random after the destructive mechanism has ceased.

Under these conditions the erythrocyte level $R_{0}$ in the normal steady state drops during an induction phase $\mathbf{R}_{\mathbf{t n d}}$ to attain an equilibrium at an abnormal steady state $\mathbf{R}^{\prime}$. When the random destructive mechanism ceases to act, the cell level of the normal steady state is resumed during a recovery phase $R_{\text {rec. }}$. This concept offers an explanation for the constant low erythrocyte level in a patient with hemolytic anemia.

the induction phase of random destruction, the steady state of random destruction, and the recovery phase.

The chief features of this conception are represented in Figure 1 by an idealized graph on Cartesian coordinates. The upper part depicts a composite of four contemporaneous crops of cells, each appearing in the circulation at a different time, persisting for four units of time and then disappearing, to be replaced by a succeeding crop. Thus the rate of cell release is represented as constant. During the normal steady state all the cells of a crop persist for four units of time when they are lost practically simultaneously as a result of aging.

Actually, of course, cell production and destruction are continuous processes. The graphic representation reflects the true state of affairs when the time intervals approach the infinitesimal and the number of cells in each crop is proportionately diminished. In a normal person the life span of the erythrocyte is probably $120 \pm 15$ days and the cell is lost from the circulation by normal aging, whatever that process may be. Henceforth, we shall refer to the life span of the normal erythrocyte, from the time when it is released to the circulation from the bone marrow until it is destroyed by the normal aging process, as the potential life span. This is actually attained only in the absence of a destructive mechanism other than normal aging.

At a certain point in the idealized figure it is conceived that a destructive mechanism begins to act constantly, catching each crop in a different stage of its life span. The cells of the crop are destroyed at random during the remainder of their potential life span, describing a curve which terminates abruptly when the potential life span is attained and the remainder of the crop is lost by aging. When the destructive mechanism ceases to 
act, there is a phase in which new crops persist normally while the pre-existing crops are still being lost in random fashion because of previous damage.

The lower portion of the graph depicts the resulting cell counts of the subject, computed as the sums of the cells in all contemporary crops. The cell level, normally $R_{0}$, decreases at the beginning of random destruction, making a curve $\mathbf{R}_{\mathbf{I n d}}$ during what we have termed the induction phase. Ultimately, an abnormal steady state $\mathrm{R}^{\prime}$ is attained which continues as long as the constant rate of random destruction obtains. This demonstrates a mechanism for the maintenance of a constant low cell count over a period of many months in a patient with hemolytic anemia. When the random destruction ceases, another transition in the cell level occurs which we have termed the recovery phase.

When the plasma volume and the distribution of erythrocytes throughout this volume remain constant, the number of cells per $\mathrm{mm}^{2}$ in any sample is a constant fraction of the total number of cells in the circulation. Even in cases in which the blood volume and the distribution of erythrocytes may not remain constant, the treatment to be presented is valid if corrected cell counts are used. It is therefore practical for this presentation to deal in cell concentrations.

\section{THE NORMAL STEADY STATE}

The normal steady state of the erythrocytes may be conceived as the result of the release from the bone marrow to the peripheral circulation of the same number of new mature cells each day and the survival of each daily crop for about 120 days, the potential life span. This situation would be represented to a closer approximation in the idealized graph in Figure 1 by 120 simultaneous crops of cells, instead of the easily pictured four.

The graph of the normal steady state may be examined in more detail in Figure 2, where crop a is succeeded by crop $e, b$ by $f, c$ by $g$, and $d$ by $h$. Each crop of cells persists for its potential life span and then is lost by aging. The number of cells in each crop is $a_{0}$ and the potential life span of each crop in the idealized graph is four units of time. The resulting cell count of the recipient $R_{0}$ at any time is the sum of the cells in each crop in the circulation simultaneously, or $4 \alpha_{0}$ in the graph. The cell level $R_{0}$ for the steady state has, of course,
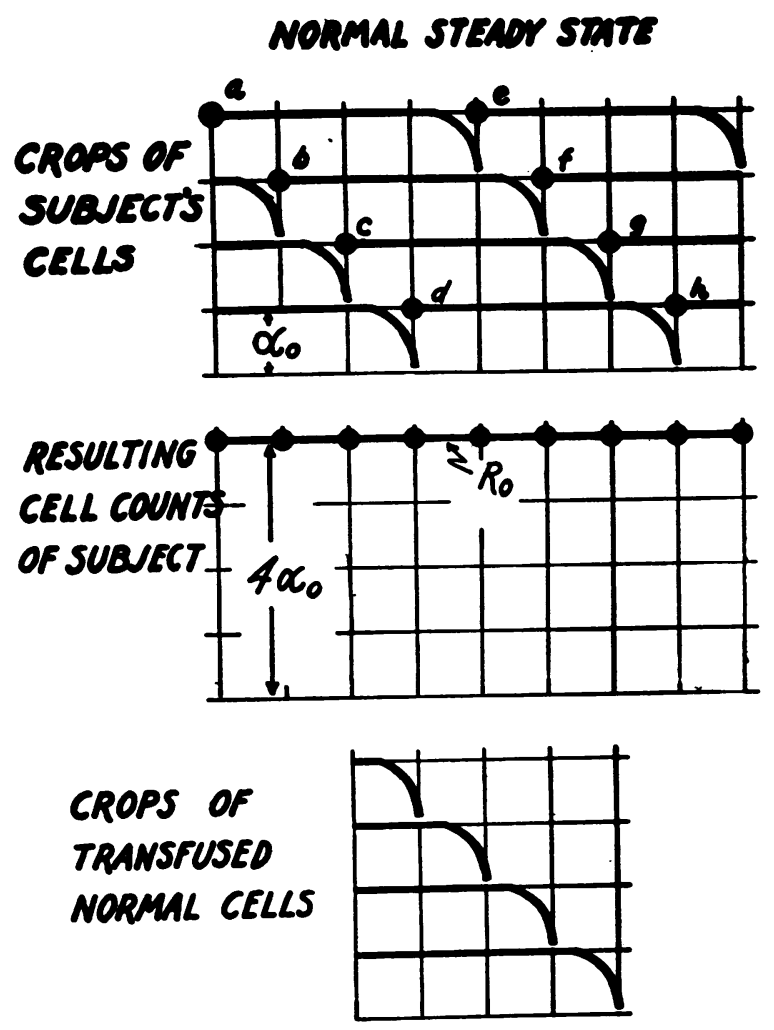

\section{RESULTING COUNTS of TRAMSFUSED CELLS}

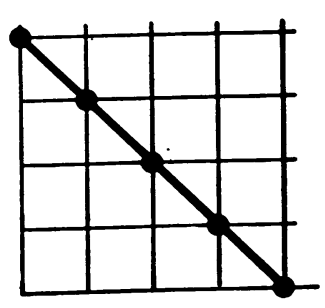

\section{TIME}

Fig. 2. Reration of Idealized Disapprarance Curves of Transfused Normal Erythrocytes to Those of Cell Crops of the Recipient in the Norimal Steady State

Values are plotted on Cartesian coordinates. The potential life span of a crop of transfused cells is assumed to be the same as a crop of the recipient's own cells, and the erythrocytes of both populations are lost only by normal aging. Unlike the crops of the recipient's cells which are replaced when lost, the transfused crops are not replaced. Hence the sums of transfused cells diminish as time passes after transfusion and the counts form a sloping straight line which intersects the time axis when the youngest of the transfused cells has attained the end of its potential life span.

been established clinically as being between 4.5 and 5.5 millions per $\mathrm{mm}^{8}$ for the adult human male.

When the subject is transfused with normal 
fresh erythrocytes during the normal steady state, the donor's cells disappear from the subject's circulation as they attain senescence. If the donor be also in the steady state when the blood is collected, the transfused blood will contain equal numbers of cells of all ages from 0 to the potential life span. The tracer cells are depicted in our model as consisting of four crops with respective ages of 0,1 , 2 , and 3 time units. The count of the transfused cells in the subject at any time is the sum of the numbers present in each transfused crop. Since

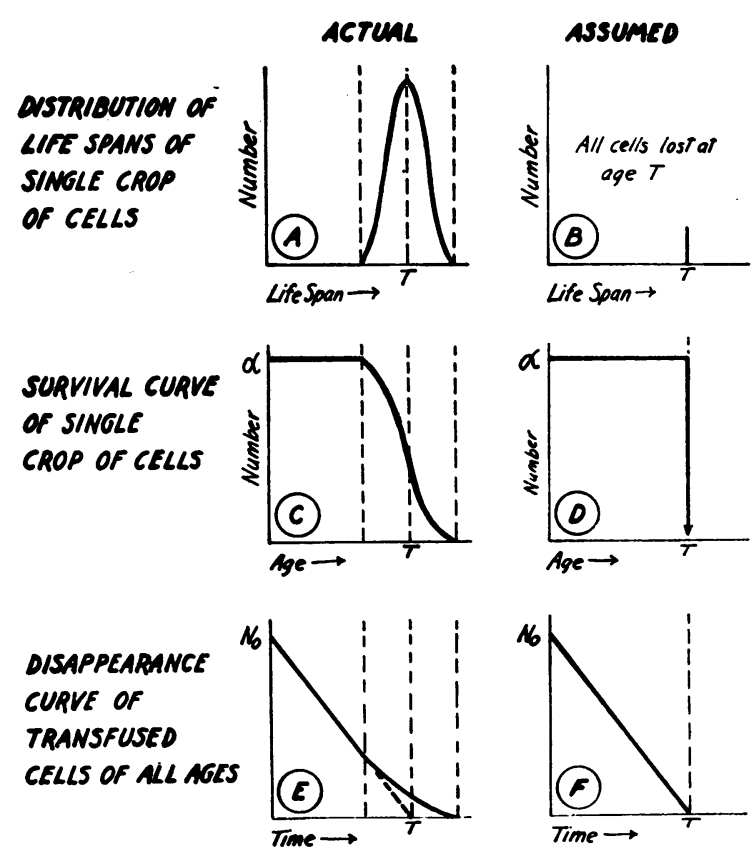

Fig. 3. Distortion of the Disappearance Curve of Inagglutinable Cells by the Assumption That All Cells of a Crop Are lost Simultaneously by Aging

The mean potential life span of erythrocytes is denoted by $T$. The distribution curve of the potential life spans of the cells of a single crop should then produce a curve as in (A). When transfused, that crop will then have a survival curve which terminates in an S-shaped segment as in (C). The composite formed by the sums of cells in many such curves of transfused crops, terminating at various times after transfusion until the youngest cell has attained its life span, is a straight sloping line until it deviates in the region of the distribution of life spans about $T$ as in (E). This is compared with the straight line slope resulting from the assumption that the distribution of life spans about $T$ is negligible as in (F). It is concluded that the error of counting of the inagglutinable cells is such as to obscure the difference between the assumed and the theoretical curves so that the simpler assumption is justified in experimental work. the crops of donor's cells are not replaced when lost, the count of transfused cells reaches zero concentration when the youngest of the donor's cells have attained their potential life span $T$. When large numbers of crops are considered, the curve of disappearance becomes essentially a straight line.

We have shown previously (2) that the equation for this straight line is

(1) $\quad \mathrm{M}=\mathrm{N}_{0}\left(1-\frac{\mathrm{t}}{\mathrm{T}}\right)=\frac{\mathrm{N}_{0}}{\mathrm{~T}}(\mathrm{~T}-\mathrm{t})$, when $0 \leqslant \mathrm{t} \leqslant \mathrm{T}$,

where $\mathbf{M}=$ concentration of cells remaining at any time $t$ when normal aging is the sole cause of loss, $N_{0}=$ concentration of donor's cells immediately after transfusion, $\mathrm{T}=$ potential life span of normal cells in days from time of release from the bone marrow to death by senescence, $\mathrm{t}=$ time after transfusion.

Therefore, $N_{0} / T$ is the number of cells in a day's crop since the number of transfused crops equals $T$. The number of cell crops still present, $t$ days after transfusion, is $\mathrm{T}-\mathrm{t}$.

Actually all cells in a crop do not disappear at precisely the same age. There is a distribution of individual life spans about the mean value $T$, as shown qualitatively in Figure 3A. The resulting survival curve in $3 \mathrm{C}$ is obtained by plotting the number of cells of this crop surviving at time $t$, against $t$. In $3 B$ the assumption is made that all cells are removed at the same age $T$, which results in the "rectangular" survival curve in 3D. It has been shown previously (2) that this assumption leads to the disappearance curve $3 \mathrm{~F}$, which is a straight line intersecting the time axis at $\mathrm{T}$ (equation 1). The actual disappearance curve resembles that depicted in $3 \mathrm{E}$ where the straight line is followed until $t$ approaches $T$, when it tails out slightly. In Figure $3 \mathrm{E}$ the effect has been emphasized by exaggeration. The straight segment has been observed by many workers, but the tailing is difficult to measure because of the experimental errors when the inagglutinable cell counts are low. Ignoring the tailing does not introduce an appreciable error in the calculation of the erythrocyte population or the rate of cell release. Hence, unless otherwise stated, the "rectangular" survival curve 3D will be assumed in the following discussion.

\section{RANDOM LOSS OF TRANSFUSED ERYTHROCYTES}

Previously (2) we have considered the mathematical implications of the random loss of transfused cells and have shown that if erythrocytes are destroyed at a constant percentage rate, irrespective of their age, the cell counts describe a curve which is the resultant of an exponential loss plus an additional loss from normal senescence. This curve 
intersects the time axis at $\mathrm{T}$ and its equation is

(2) $N=N_{0}\left(1-\frac{t}{T}\right) e^{-b t}=(T-t) \frac{N_{0}}{T} e^{-b t}$, when $0 \leqslant t \leqslant T$,

where $\mathrm{N}_{0}=$ concentration of donor's cells immediately after transfusion, $\mathrm{T}=$ potential life span of cells from release from the bone marrow until death by normal senescence, $t=$ time after transfusion, $N=$ count of donor's cells at time $t, e=$ base of natural logarithms, and $b=$ constant percentage rate of random destruction (e.g., if 2 per cent of the surviving cells are lost per day, then $\mathrm{b}=0.02),(\mathrm{T}-\mathrm{t})=$ number of remaining crops, and $\left(\frac{N_{0}}{T} e^{-b t}\right)=$ number of cells in each surviving crop at time $t$.

The rate of random loss of the transfused cells may be calculated by an adjustment of the observed values for the inagglutinable cell counts to compensate for loss by normal aging. This is equivalent to a manipulation which abolishes all loss by aging so that the disappearance from random destruction is sharply defined. For this purpose it is convenient to introduce a quantity $Q$, which is a function of time, and is defined by the equation:

(3) $Q=\frac{N}{M}=\frac{N}{N_{0}\left(1-\frac{t}{T}\right)}$, when $0 \leqslant t \leqslant T$,

where the symbols have the same meaning as in equation 1.

In the practical determination of the $Q$ curve it is usually more convenient to rewrite equation 3 thus :

$$
N_{0} Q=\frac{N}{1-\frac{t}{T}}
$$

$\mathrm{N} \circ \mathrm{Q}$ can then be considered as the count of transfused cells with infinite potential life spans whose actual life spans thus terminate only by random destruction. The values for $N_{0} Q$ are calculated, rather than those for $Q$. This obviates the necessity for estimating any value for $N_{0}$ at the beginning. The first inagglutinable cell count may be unsatisfactory to employ as $N_{0}$ because too much emphasis is placed on a single determination. Once the $N_{0} Q$ values have been plotted and a smoothed curve drawn through the points, $\mathrm{N}_{0}$ may be estimated by finding where the curve intersects the vertical axis $t=O$, because at this point $Q=1$. The scale of ordinates for the $N_{0} Q$ curve runs from $O$ to $N_{0}$. The graph made by values of $N_{0} Q$ can also be used as a graph of $Q$ by substituting a vertical scale from $O$ to 1 .

To construct a model, such as is pictured in Figure 1, specific modes of action of the destructive mechanism must be assumed. In this case we have chosen to consider a hypothetical situation which is a composite of several examples confronting us in our experimental studies to be presented in later papers. The assumptions are: (a) The destructive mechanism acts on all cells of each crop at random; (b) at the beginning of action of the destructive mechanism the cells of all crops are damaged simultaneously and irrespective of age so that random destruction starts in all crops at the same time; (c) when the destructive mechanism ceases, the damaged cells of the pre-existing crops continue to be lost at random throughout the potential life span of the crops, whereas the cells of the new crops are undamaged.

For the purposes of this discussion it is necessary to expand the meaning of the term random destruction. The reader is perhaps accustomed to thinking of the steady state of random destruction as implying that the percentage rate of loss must be constant. However, the authors do not conceive this as being necessarily true. Let it be supposed that the cells of any given crop are destroyed at random, but the percentage rate of loss varies with the time which has elapsed since the destructive mechanism first began to act on the cells of this particular crop. Then, if the disappearance curve of the crop is plotted on semilogarithmic coordinates, a straight line will not result, and the curve is not exponential in the usual sense. Yet, if the disappearance curves of successive crops (depicted in Figure 1) are congruent, a steady state will exist, provided the rate of cell release is constant.

The implications of this hypothesis for three particular groups of cell crops are: (a) For cell crops present in the subject at the inception of the induction phase, the destructive mechanism begins to act at the inception of the phase; hence, the percentage rate of random destruction for these crops depends on the length of time since the beginning of the phase. The age of the cells at the beginning of the phase is inconsequential. (b) For cell 
crops produced after the beginning of the induction phase, the destructive mechanism begins acting at the time the cells are extruded into the circulation; hence, the percentage rate of random loss for these crops varies with the age of the cells. (c) For crops of transfused cells, the destructive mechanism begins to act at the time of transfusion; hence, the percentage rate of random loss for these crops depends on the length of time since transfusion. It does not depend on the age of the cells at the time of transfusion.

If it be assumed that the disappearance curves of successive crops of cells are congruent, and the transfused crops of cells are destroyed in the same manner as the subject's cells, then it follows that the disappearance curve of the transfused cells will be the same, regardless of the time at which it is determined. This situation may be termed a "constant process of random destruction." It is presumed to exist from the beginning of the induction phase, through the steady state of random destruction, to the beginning of the recovery phase.

\section{Graphic Demonstration of Random Loss}

Cartesian coordinates. When the $\mathrm{N}_{0} Q$ values are calculated from the observed counts for the inagglutinable cells by the use of equation 4 , they may be plotted on Cartesian (ordinary rectangular) coordinates. If there has been no random loss of cells, a straight horizontal line is formed when the $N_{0} Q$ values are plotted on the vertical axis and time after transfusion $t$ is plotted on the horizontal axis. If, however, there is random loss, in addition to disappearance by normal aging, the resulting curve will be curvilinear and lie above the curve of the observed values for the inagglutinable cell counts (Figure 4 ). The $N_{0} Q$ curve may approach, but never reaches, the horizontal axis whereas the curve of observed values intersects the time axis at $\mathrm{T}$, the mean potential life span of the cells. This method of plotting demonstrates the presence or absence of random destruction of the inagglutinable cells, but gives no obvious information as to the percentage rate of random loss. Plotting on Cartesian coordinates is, however, necessary to obtain the area under the $\mathrm{N}_{0} \mathrm{Q}$ curve employed in certain methods to be discussed later.

Semilogarithmic coordinates. When the $\mathrm{N}_{0} \mathrm{Q}$ values are plotted on a vertical semilogarithmic scale against values for time $t$ on the horizontal rectangular scale, the curve is a horizontal straight line when there has been no random loss (Figure 4). A straight line sloping downward to the right
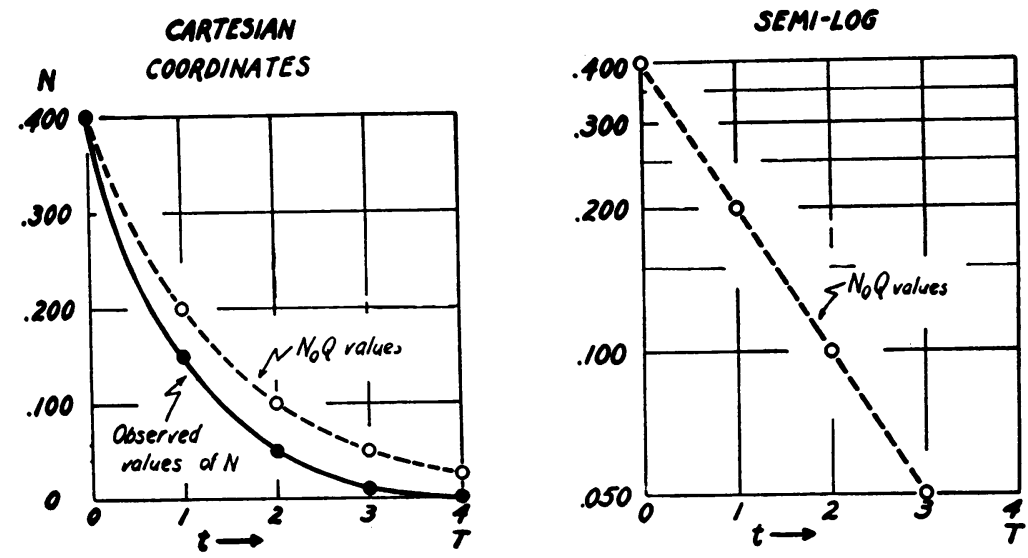

Fig. 4. Measurement of Rate of Random Loss by Graphic Methods

The solid line curve on Cartesian coordinates was constructed from values for inagglutinable cell counts $N$ on the assumption that the potential life span $T$ of the transfused cells was 4 time units and that there was a constant random destruction, in addition to loss by aging. The $\mathrm{N} . Q$ values were then calculated, using equation 4 , and form the curve of broken lines which approaches the time axis, but never intersects it. Plotting the N.Q values on semilog coordinates produces a straight line with slope downward to the right. When the curve of $\mathrm{N}$.Q values deviates from the horizontal (in either system of coordinates) there has been random loss of transfused cells. A straight line slope on semilog coordinates indicates a constant percentage rate of random loss. The slope of the line gives the percentage rate of loss. 
indicates random loss in exponential fashion, i.e., at a constant percentage rate. The slope of the curve is proportional to the percentage rate of loss. Thus if the sloping curve is not a straight line but deviates toward the horizontal, there is deceleration in the percentage rate of loss; if the curve deviates toward the vertical, the percentage rate is accelerating. This method of plotting, therefore, indicates not only the presence of random loss of cells but also gives information as to the rate of random loss. The example plotted in Figure 4 shows observed values corresponding to equation 2 from which $\mathrm{N}_{0} Q$ values were calculated by equation 4 . The constant rate of random loss represented here is a special case of our more general hypothesis, but it occurs very commonly.

In equations 3 and 4 we have taken the simple expression for $M$, based on the rectangular approximation of the cell survival curve in Figure $3 D$, so that $M=O$ at $t=T$. If $N \circ Q$ is to have a finite value at $t=T, N$ must also be $O$. Since the rectangular survival curve is not an accurate description of nature, experimental values of $\mathrm{N}$ are found to have a small value greater than $O$ at $t=T$. This makes $N_{0} Q$, as determined by equation 4, approach infinity as $t$ approaches $T$. This difficulty can be obviated by incorporating in equations 3 and 4 an expression for $M$ corresponding to the more accurate description shown in Figure 3E. In practice, however, it is more convenient if the end portion of the N.Q curve is determined by extrapolation from the region in which Figure $3 F$ and equation 1 are accurate descriptions. The exact shape of the N.Q curve near the end, in any event, does not markedly affect the results of the graphic methods to be presented.

In calculating values for $\mathrm{N}_{0} \mathrm{Q}$ in equation 4 it is necessary at the outset to select a value for $T$, since the mathematical form of $Q$ is unknown. This is often difficult experimentally because the actual counts of the donor's cells merge gradually into the blank counts of the subject's own inagglutinable cells. An error in the selection of the value for $\mathrm{T}$ results in a curved line when the $N_{0} Q$ values are plotted on semilog paper. This curvature can be misinterpreted as indicating changes in the rate of random destruction. The probability of such an error can be lessened by calculating the $N_{0} Q$ values with several assumptions for $T$. In practice it often happens that no value for $\mathrm{T}$ can be found which gives a straight line curve, in which case it seems most practical to assume $T=120$ days, unless there is definite evidence to the contrary.
Fortunately, during the first 60 to 90 days of a transfusion study, the calculations of $\mathrm{N}_{0} \mathrm{Q}$ are relatively insensitive to slight errors in the value chosen for $T$. But when $t$ approaches $T$, slight changes in the value for $T$ make large differences in the $N_{0} Q$ values. The effect of the assumption of the rectangular survival curve on the $\mathrm{N}_{0} Q$ values has previously been discussed. For these reasons, most emphasis should be placed on the $\mathrm{N}_{0} \mathrm{Q}$ values during the first 60 to 90 days. In this paper $\mathrm{T}$ will be assumed to be the same for both donor's and subject's cells.

The theoretical implications of the $Q$ curve are wider than so far indicated. In an earlier paper (2) we used the equation

(5) $\frac{d M}{d t}=-\mathrm{aN}_{0} ; \quad M=N_{0}(1-a t)$, when $0 \leqslant t \leqslant T$, where $\mathrm{N}=$ number of observed inagglutinable cells at time $t$ after transfusion, $M=$ number of cells at time $t$ if there were no loss except by aging, $N_{0}=$ number of donor's cells immediately after transfusion, $a=$ constant of proportionality or $1 / \mathrm{T}, \mathrm{T}=$ potential life span of normal cells from time of release from the bone marrow to death by senescence. If some of the donor's cells are destroyed at random irrespective of their age, the concentration actually present at time $t$ is less than $M$ and this quantity can be represented by $N$. Since all crops present at time $t$ have been exposed to the destructive mechanism for the same length of time, they have all been reduced in numbers by the same fraction N/M. Furthermore, the number in the crop lost by normal aging at that time is only $\mathrm{N} / \mathrm{M}$ times as large as it would have been without random destruction. Thus the rate of disappearance from normal aging is $-(\mathrm{N} / \mathrm{M}) \mathrm{aN}_{0}$. This expression includes only the cells which are lost by normal aging.

Assume that the random destructive mechanism removes cells at a rate proportional to the number of cells present and a coefficient which depends upon the length of time since the cells were first exposed to the destructive factor. Then the rate of removal of the cells by this mechanism becomes $-k(\lambda) N$, where $\lambda=$ length of time since first exposure, and $k(\lambda)$ is the percentage rate of destruction of cells after time $\lambda$. If the donor's cells are first exposed to the destructive mechanism at the time of transfusion, both $\lambda$ and $t$ are measured from the same point, hence $\lambda=t$, and the rate of removal due to the destructive mechanism is $-k(t) N$. The total rate of removal is then:

$$
\frac{d N}{d t}=-\frac{N}{M} \mathrm{aN}_{0}-k(t) N
$$

Integration of equation 6 yields

(7) $N=(T-t) \frac{N_{0}}{T} e^{-S_{0}^{t} k\left(t^{\prime}\right) d t^{\prime}}$, when $0 \leqslant t \leqslant T$,

where $t^{\prime}=$ any value of time between $O$ and $t$. 
Since $Q$ has been defined in equation 3 as $Q=N / M$, therefore

$$
Q=e^{-S_{0} t^{\prime}\left(t^{\prime}\right) d t^{\prime}}, \text { when } 0 \leqslant t \leqslant T .
$$

The special but common case, in which $k\left(t^{\prime}\right)$ has some constant value $b$, gives the expression used in equation 2: $Q=\mathrm{e}^{-\mathrm{bt}}$, when $k\left(t^{\prime}\right)=b$.

No cells of the crop extruded from the bone marrow precisely at the time of transfusion of tagged cells are lost by aging during the transfusion experiment because the study coincides with their life span. If the subject's cells are destroyed in the same manner as those of the donor, one gets the following:

$$
\frac{\mathrm{dr}}{\mathrm{dt}}=-\mathrm{k}(\lambda) \mathrm{r},
$$

where $r=$ number of subject's cells in the crop at time $t$ and $\lambda=$ length of time since cells were first exposed to the destructive mechanism. In this case, also, $\lambda=t$. Hence

$$
\begin{gathered}
\frac{d r}{d t}=-k(t) r, \\
\frac{r(t)}{r_{0}}=e^{-\int_{0}^{t} k\left(t^{\prime}\right) d t^{\prime},}
\end{gathered}
$$

where $r_{0}$ is the original number of cells in the crop. From equations 8 and 11

$$
\frac{r(t)}{r_{0}}=Q(t) .
$$

The expression $r(t) / r_{0}$ gives the proportion of cells of the crop which survive at time $t$, hence at age $t$. Thus $Q(t)$ is also the survival curve for this crop of cells. Since it is assumed that each crop is treated similarly, regardless of the time of appearance in the circulation, $Q(t)$ is the survival curve giving the probability that any cell will survive at least to age $t$. The symbol $\phi(t)$ has been employed by other workers (3-5) to designate this probability. Therefore the technique of differential agglutination after transfusion affords a reasonably direct method of determining the cell survival curve.

\section{STEADY STATE DURING RANDOM DESTRUCTION}

After the constant process of random destruction of the subject's erythrocytes has been in operation for sufficient time, his erythrocyte counts cease to decrease but stabilize at a level below that of the normal steady state $R_{0}$ (Figure 1 ). The new steady state is maintained as long as the rate of cell release remains constant and the random loss is unchanged.

Detailed examination of this abnormal steady state is assisted by study of Figure 5. Originally each crop is composed of the same number of cells, and for the present case this number is assumed to be the same as for those crops formed during the normal steady state. Each crop has an identical but abnormal disappearance curve. The resulting erythrocyte level $R^{\prime}$ is the sum of the numbers of
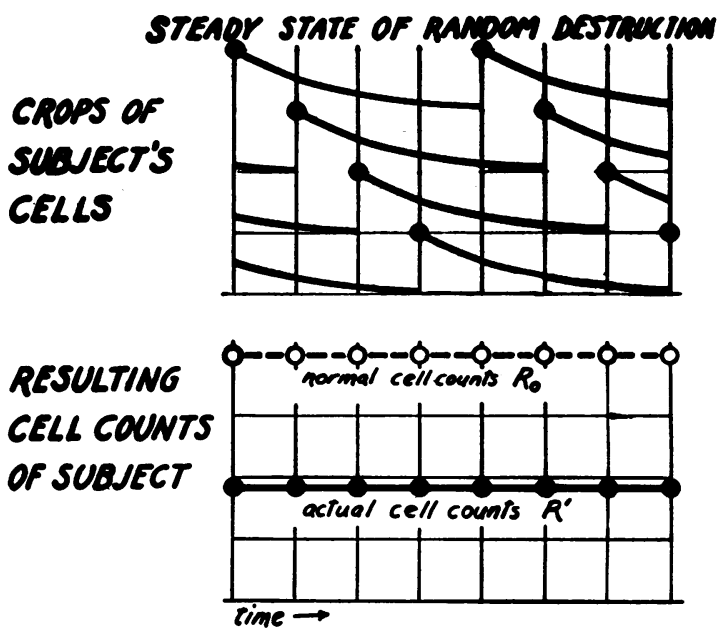

TRANSFUSED CELL CROPS DESTROYED OY SAME MECHANISM
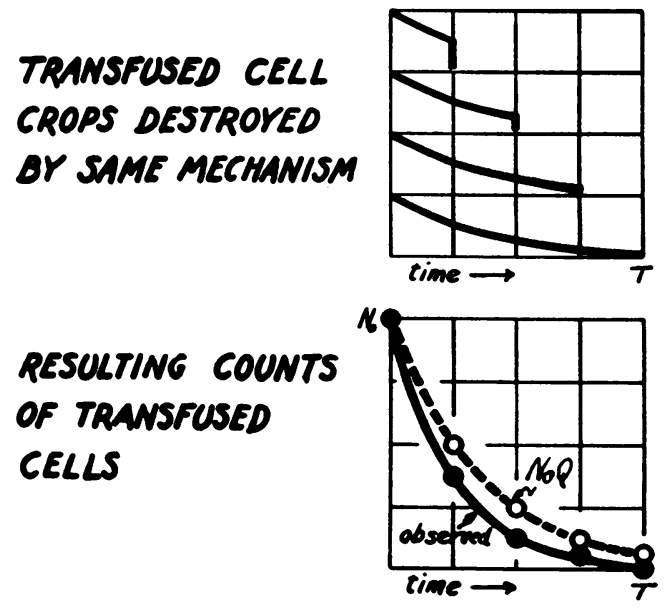

Fig. 5. Relation of Disappearance Curve of Transfused Normal Erythrocytes to Cell Loss in Single Crops of Recipient during Steady State of Random DESTRUCTION

During this phase the loss of the cells in each crop of the recipient is depicted as a curve which ceases at the termination of the potential life span when the number of cells abruptly falls to zero as the remainder is lost by aging, to be replaced by a new crop. The component crops of the transfused cells are similarly lost except that a larger proportion of each crop is lost by aging and there are no replacements. The sums of inagglutinable cells in the crops present at various times form a disappearance curve, depicted by the solid line, which actually intersects the time axis at $T$. When the loss of inagglutinable cells by aging is compensated for in the computation of the N.Q values by equation 4 , a curve (broken line) results which can be made congruent with the disappearance curve of any single cell crop of the subject. 
cells of all crops contemporaneous at any time $t$, but the contribution of any one crop differs from all the others.

The lower half of Figure 5 depicts the fate of normal erythrocytes transfused to the subject during this steady state, if the donor's cells are destroyed in the same manner as those of the subject. The disappearance curves of the crops of donor's cells are similar to those of the subject, except that the older crops are lost by aging before as many cells can be destroyed at random. The sums of the numbers of cells in the transfused crops at any time $t$ equal the inagglutinable cell count expressed by equation 7 . The values for $N_{0} Q$ can be computed from the observed counts using equation 4 .

The addition of increments of staggered crops of recipient's cells at time $t$ is equivalent to adding the cells present at successive time units on a single curve of disappearance or survival. This is illustrated in Figure 6 in which a curve for a single crop has been divided into vertical rectangles the sum of whose heights approximates $R^{\prime}$. The accuracy of this relation increases when the number of time units, and hence the number of rectangles, is enhanced beyond the limit of graphic presentation. Actually this is the method of integral calculus in determining an area under a curve. Similarly, division of the rectangle enclosing the survival curve for the crop into smaller vertical rectangles shows that the sum of their heights equals $R_{0}$, the erythrocyte level of the subject when there is no random destruction. Hence $R^{\prime}$ can be represented by the area $X$, and $R_{0}$ by the area $X+X^{\prime}$ so that

$$
\frac{\mathrm{R}^{\prime}}{\mathrm{R}_{0}}=\frac{\mathrm{X}}{\mathrm{X}+\mathrm{X}^{\prime}}
$$

The cell level $R^{\prime}$ could be calculated from the areas $\mathrm{X}+\mathrm{X}^{\prime}$ if these were known, but no methods are presently available for the direct measurement of a single crop of cells, although composites of the crops of a few days have been measured by labeling the subject's erythrocytes with $\mathrm{N}^{15}(6)$ or $\mathrm{C}^{16}(7)$.

Relative values for $\mathrm{X}$ and $\mathrm{X}^{\prime}$ may be obtained by the transfusion of biologically tagged cells to the subject, provided that the donor's cells are destroyed in the same manner as the subject's and that the potential life spans of the cells in the two populations are the same. Thus in Figure 6 both the upper and lower rectangles have the same base, and the height of the $N_{0} Q$ curve of the transfused cells has been proven to be everywhere proportional to that of the disappearance curve of the single crop. These curves can, in fact, be made congruent by drawing them on the same scale. Therefore

$$
\frac{\mathrm{X}}{\mathrm{X}+\mathrm{X}^{\prime}}=\frac{\mathrm{Y}}{\mathrm{Y}+\mathrm{Y}^{\prime}}
$$

and from equation 13 we have

(15) $\frac{\mathrm{R}^{\prime}}{\mathrm{R}_{0}}=\frac{\mathrm{Y}}{\mathrm{Y}+\mathrm{Y}^{\prime}}$ or $\mathrm{R}^{\prime}=\mathrm{R}_{0}\left(\frac{\mathrm{Y}}{\mathrm{Y}+\mathrm{Y}^{\prime}}\right)$.

This relation applies to any shape of disappearance curve, provided that the curve of the single crop can be made congruent with the $N_{0} Q$ curve. The principal conditions for this are that the recipient's and donor's cells be destroyed at the same rate, i.e., the same $k(\lambda)$, and that they have the same potential life span $T$.

The mathematical proof of equation 15 follows. Callender, Powell, and Witts (3) pointed out that the mean cell life $\bar{\tau}$ (i.e., actual mean cell life, whether the loss is by aging or random destruction) is represented by the area under the survival curve. Thus, by our assumptions, $\bar{\tau}$ equals the area under the $Q$ curve between $t=O$ and $\mathrm{t}=\mathrm{T}$ in equation 3 . Using the symbolism of calculus,

$$
\bar{\tau}=\int_{0}^{T} Q(t) d t .
$$

In any steady state the total number of cells must be the product of the actual mean life span and the rate of production. Hence, if $\alpha_{0}$ is the normal rate of cell release, $R_{0}$ the resulting normal erythrocyte count, and $R^{\prime}$ the erythrocyte count in the steady state of random destruction during a normal rate of cell release,

$$
\begin{gathered}
\mathrm{R}_{0}=\alpha_{0} \mathrm{~T} \\
\mathrm{R}^{\prime}=\alpha_{0} \bar{\tau} \\
\frac{\mathrm{R}^{\prime}}{\mathrm{R}_{0}}=\frac{\alpha_{0} \bar{\tau}}{\alpha_{0} \mathrm{~T}}=\frac{\mathrm{N}_{0} \bar{\tau}}{\mathrm{N}_{0} \mathrm{~T}} .
\end{gathered}
$$

From equations 16 and 19 we have

$$
\frac{R^{\prime}}{R_{0}}=\frac{N_{0} \int_{0}^{T} Q d t}{N_{0} T}=\frac{\int_{0}^{T} N_{0} Q d t}{N_{0} T}=\frac{Y}{Y+Y^{\prime}} .
$$

\section{Graphic Method for Estimating Rate of Cell Release}

In practice the estimation of $\mathrm{R}^{\prime}$ in equation 15 is relatively simple. The observed inagglutinable cell counts are recalculated according to equation 4 to obtain the $N_{0} Q$ values. The latter are plotted on the vertical axis of Cartesian coordinates, against 
days after transfusion on the abscissa. A smoothed curve is drawn through the points. This curve will not intersect the time axis. As shown in Figure 6, a rectangle is constructed with the vertical axis of the graph as the left side, the horizontal axis from $O$ to $T$ as the base, a vertical line at $T$ as the right side; and the top is formed by a horizontal

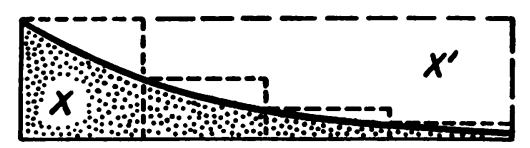

Single crop of subject's cells with constant rate of rendom loss

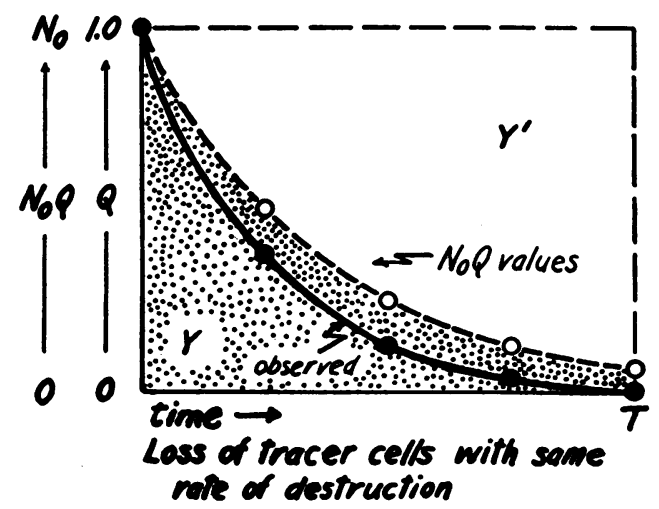

Fig. 6. Graphic Estimation of Erythrocyte Level of the Subject in the Steady State of Random Destruction

Reference to Figure 5 shows that the subject's erythrocyte count $\mathbf{R}^{\prime}$ in the steady state of random destruction is the sum of the numbers of contemporaneous cells in the four crops. Each crop makes a different contribution to the sum since a vertical line at time $t$ cuts each disappearance curve at a different time in its life span. The same value for $R^{\prime}$ can be obtained by cutting the disappearance curve of a single crop into vertical rectangles for each time unit, as in the present figure, and adding the vertical lengths together. If there were no loss by random destruction, the disappearance curve of a single crop would form the rectangle $\mathrm{X}+\mathrm{X}^{\prime}$ and its component vertical rectangles, when added together, would give the cell level $R_{0}$ in Figure 5. But the data of a single crop are not available for measurement whereas it has been shown that the $N_{\circ} Q$ values of normal transfused cells, destroyed in the same random fashion as those of the subject, form a curve which can be made congruent with the disappearance curve of a single crop of the subject's cells. Therefore

$$
\frac{R^{\prime}}{R_{0}}=\frac{X}{X+X^{\prime}}=\frac{Y}{Y+Y^{\prime}} \text { or } R^{\prime}=R_{0}\left(\frac{Y}{Y+Y^{\prime}}\right)
$$

The areas $Y$ and $Y+Y^{\prime}$ may be measured with a planimeter. line through the intersection of the $\mathrm{N}_{0} Q \mathrm{Q}$ curve with the vertical axis. When the exact value for the subject is unknown, $\mathrm{T}$ is usually taken as 120 days. The area under the curve is $\mathrm{Y}$ and the remainder of the area of the rectangle is $Y^{\prime}$. The area $Y$ is measured with a planimeter and the area of the rectangle $\mathrm{Y}+\mathrm{Y}^{\prime}$ may be obtained in the same manner or by inspection of the graph paper.

The value for $R^{\prime}$ is computed from equation 15 in which $R_{0}$ is usually taken as equal to 5 millions per mm..$^{8} \quad R^{\prime}$ is the level of the subject's erythrocytes to be expected when (a) the rate of cell release is normal, (b) the subject's cells are lost at random in the same manner as the tracer cells, regardless of the shape of the disappearance curve, (c) the potential life span of the two cell populations is approximately equal, $(d)$ the subject is in a steady state during random destruction of erythrocytes.

The subject's actual erythrocyte counts are obtained by subtracting the inagglutinable cell count from the contemporaneous total cell count. The actual cell counts of the subject are then compared with the values computed for $R^{\prime}$ and, when they are significantly higher or lower, it is concluded that the rate of cell release is greater or less than normal.

More precisely, the rate of cell release must be proportional to the observed cell count. Thus

$$
\frac{\alpha^{\prime}}{\alpha_{0}}=\frac{\text { actual cell level }}{R^{\prime}} \text { and } \alpha^{\prime}=\frac{\text { actual cell level }}{R^{\prime}} \cdot \alpha_{0} \text {, }
$$

where $\alpha_{0}=$ normal rate of cell release, $\alpha^{\prime}=$ rate of cell release during the steady state of random destruction.

It is of interest that Dornhorst (5) has used a similar graphic method for estimating the mean cell life when normal blood is transfused to a patient with a hemoclastic anemia.

Since correct values for $R_{0}$ and $T$ are not always known for the subject of a study, it is worthy to note the manner in which errors in assuming values affect the calculated values for $R^{\prime}$ and $\alpha^{\prime} / \alpha_{0}$. Analysis reveals that when the random destruction is very slight, an error in assuming a value for $T$ produces a much smaller error in $R^{\prime}$. But if the random destruction is great, the error in assuming a value for $T$ is carried over undiminished in calculating $R^{\prime}$. In any case, the sense of the error is reversed: if $T$ is too large, $R^{\prime}$ is too small. Any error in the assumed value of $R_{0}$ appears undiminished in the calculated $R^{\prime}$; if $R_{0}$ is taken too large, $R^{\prime}$ is proportionately large. Any error in the calculation of $R^{\prime}$ is transmitted undiminished to the calculated value of the ratio $\alpha^{\prime} / \alpha_{0}$, but it is reversed in sense. 
Errors in counting cells are minimized in these graphical methods because little emphasis is placed on a single determination. In measuring the erythrocyte level of the subject, counts are made on several days and a mean is taken. In determining the disappearance curve of transfused cells, the points are plotted and a smooth "average" curve is drawn. These procedures serve to minimize the effects of random short-term variations in blood volume.

The other principal assumptions are best considered when the methods are applied to individual cases. The plausibility of assuming no systematic change in blood volume and the same rate of random destruction for the erythrocytes of donor and recipient depend entirely on the specific conditions of the individual study.

With the present level of refinement in the experimental methods these graphic analyses are most useful for demonstrating gross changes in the rate of cell release, for example, when $\alpha^{\prime}$ is two or more times as great as $\boldsymbol{\alpha}_{0}$. However, if ways are found to better evaluate $T$ and $R_{0}$ and to remove some remaining uncertainties concerning the basic hypotheses, these graphic methods may be useful in demonstrating more delicate changes in the rate of numerical cell production.

\section{INDUCTION PHASE OF RANDOM DESTRUCTION}

In Figure 1 the erythrocyte level of the subject describes a curve $R_{\text {ind }}$ which commences to descend from the normal level $R_{0}$ to a lower level $R^{\prime}$ at the beginning of the period of random destruction. In certain experiments it is useful to predict this transition curve. The expanded graph in Figure 7 shows that the tagged cells have the same curve of loss as they have in the steady state of random destruction in Figure 5. The subject's cells may be considered in two groups (a) those present at the beginning of the induction phase, "pre-existing cells," and (b) cells released to the circulation after the beginning of the induction phase, "new cells." It will be assumed that the time taken to change from the normal state to that of random destruction is negligibly brief. After the change occurs, a time $T$ must elapse before the steady state of random destruction is attained.

Each crop of "pre-existing cells" is removed in the manner shown by the $Q$ curve in Figure 8 until it reaches the end of its potential life span when the remainder is lost by aging. Each crop is assumed to have the same initial number of cells and the rate of random destruction of each crop is assumed to be the same. Therefore, the number of cells remaining in each crop at any time $t$ is the same, and is proportional to the ordinate of the $Q$ curve at the time. The number of surviving crops
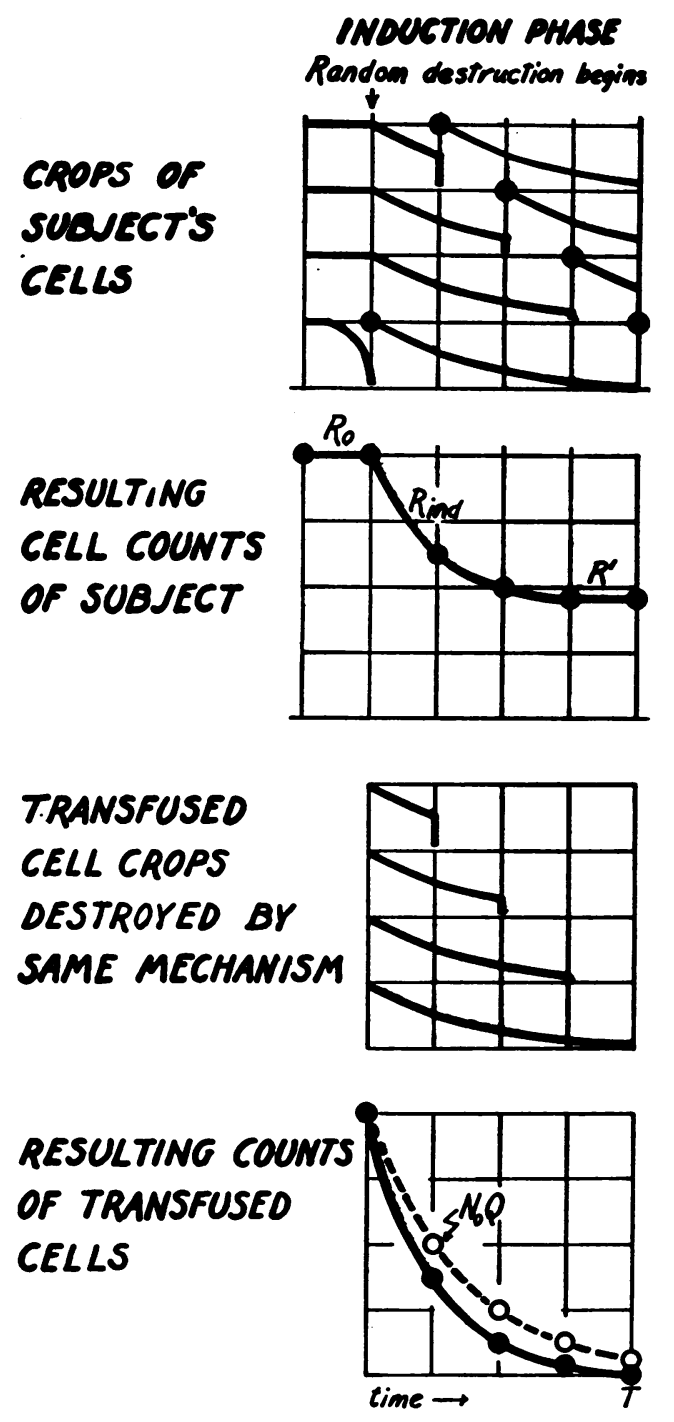

Fig. 7. Relation of the Disappearance Curve of Transfused Normal Cells to the Decreasing Cell Counts of the Subject during the Induction Phase of Random Destruction

For purposes of this example it is assumed that each cell crop exposed to the destructive mechanism is similarly damaged so that its cells are lost at random irrespective of their ages. During this phase the sums of the cells in the "pre-existing" crops are lost in a curve congruent with the disappearance curve made by the observed values for the inagglutinable cells transfused during this period. The decreasing values for the subject's cell count form a curve $R_{\text {ind }}$ of two components, one the "preexisting" cells and the other the cells formed after random destruction has begun.

is $\mathrm{T}-\mathrm{t}$, since the other crops will have been lost by senescence. The total number of "pre-existing cells" remaining at any time $t$ is therefore propor- 
tional to the product $(T-t) \cdot Q(t)$, which is the densely stippled area in Figure 8.

The production and loss of "new" cells may be followed in Figure 7. Still assuming that the rate of cell release remains normal, the total number of "new" cells at any time $t$ is the sum of the cells remaining in all crops which have been released up to that time. The contribution of one crop to the sum is different from that furnished by any other at that time. The addition of increments of staggered crops is equivalent to adding the number of cells present at successive units of time on a single curve. This reasoning has been employed previously in discussing the steady state of random destruction. In the induction phase, however, the number of "new" cells present at time $t$ is the sum of the cells in the new crops produced prior to $t$. This sum is represented by the area under the $Q$ curve in Figure 8 between $O$ and $t$, shown as the sparsely stippled portion.

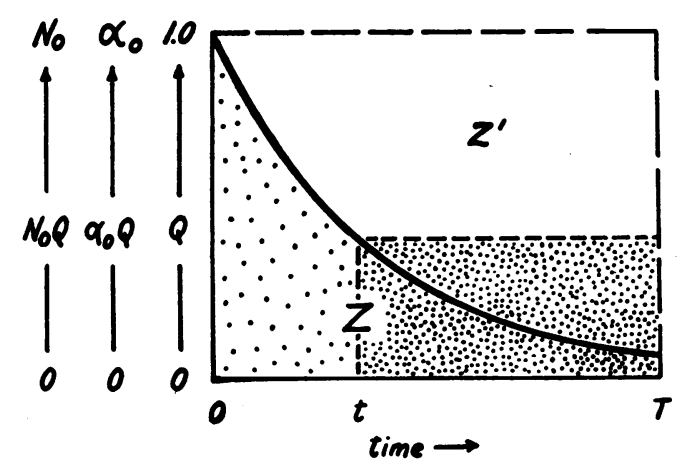

Fig. 8. Graphic Estimation of the Descending Curve of Erythrocyte Counts in the Subject during the Induction Phase of Random Destruction

The problem is to construct curve $R_{\text {ind }}$ in Figure 7 when $R_{0}$ is known, the cell release rate is normal, and the rate of random destruction is measurable from the disappearance curve of the inagglutinable cell counts. The time $T$ is the potential life span of normal erythrocytes, generally 120 days. The curve is constructed from the $N_{\circ} Q$ values of the inagglutinable cell counts obtained with equation 4. The intersection of the curve with the vertical axis determines $N_{0}$. At any time $t$ the number of remaining "pre-existing" cells is represented by the densely stippled area, whereas the number of "new" cells is represented by the sparsely stippled area. The entire stippled area is designated $Z$ and the unstippled remainder of the rectangle is $Z^{\prime}$. These areas may be measured by a planimeter. Points on the curve $R_{\operatorname{lna}}$ are determined for various times $t$ according to the relation

$$
\frac{R_{\text {ind }}}{R_{0}}=\frac{Z}{Z+Z^{\prime}} \text { or } R_{\text {ind }}=R_{0}\left(\frac{Z}{Z+Z^{\prime}}\right) \text {. }
$$

The total number of cells at time $t$ is $R_{\text {Ind }}$, which is represented in Figure 8 by the entire area which is stippled, either densely or sparsely, now called $Z$. As before, $R_{0}$ is proportional to $Z+Z^{\prime}$ and at any time $t$

$$
\frac{R_{\text {ind }}}{R_{0}}=\frac{Z}{Z+Z^{\prime}}, \quad R_{\text {ind }}=R_{0}\left(\frac{Z}{Z+Z^{\prime}}\right) .
$$

As in the steady state, the ratio of these areas can be determined as well from a plot of $N_{0} Q$ values as from $Q$ itself.

The mathematical proof for equation 22 follows: At any time $t$ (measured now from the beginning of the induction phase) the pre-existing cells $R_{1}$ have ages between $t$ and $T$. The number of daily crops is $T-t$ and each crop has been reduced from its original size $\alpha_{0}$ to $\alpha_{0} Q(t)$. Thus the total number of pre-existing cells is

$$
R_{1}(t)=\alpha_{0} Q(t)(T-t)
$$

At time $t$ the new crops have ages between $O$ and $t$. The number of cells in a crop of age $t^{\prime}$ (between $O$ and $t$ ) is $\alpha_{0} Q\left(t^{\prime}\right)$. Adding all the new crops gives the number of new cells $R_{\mathbf{2}}$ :

$$
R_{3}(t)=\int_{0}^{t} \alpha_{0} Q\left(t^{\prime}\right) d t^{\prime}=\alpha_{0} \int_{0}^{t} Q\left(t^{\prime}\right) d t^{\prime} .
$$

The total number of cells then is

$$
\begin{aligned}
R_{\text {ind }}(t)=R_{1}+ & R_{2} \\
& =\alpha_{0}\left(Q(t)(T-t)+\int_{0}^{t} Q\left(t^{\prime}\right) d t^{\prime}\right) .
\end{aligned}
$$

It has already been shown that

$$
\mathrm{R}_{0}=\alpha_{0} \mathrm{~T} \text {. }
$$

Combining equations 17 and 25 yields

$$
\frac{R_{\text {ind }}(t)}{R_{0}}=\alpha_{0} \frac{\left(Q(t)(T-t)+\int_{0}^{t} Q\left(t^{\prime}\right) d t^{\prime}\right)}{\alpha_{0} T} .
$$

Multiplying the numerator and denominator by $N_{0} / \alpha_{0}$ gives

$$
\begin{aligned}
\frac{R_{\text {ind }}(t)}{R_{0}} & =\frac{N_{0} Q(t)(T-t)+\int_{0}^{t} N_{0} Q\left(t^{\prime}\right) d t^{\prime}}{N_{0} T} \\
& =\frac{Z}{Z+Z^{\prime}} \\
R_{\text {ind }}(t) & =R_{0}\left(\frac{Z}{Z+Z^{\prime}}\right) .
\end{aligned}
$$

\section{Graphic Method for Estimating Rate of Cell Release}

The problem is to construct the expected curve of the subject's erythrocyte counts if the rate of production of cells proceeds at a normal rate and if the inagglutinable cell counts, or other condi- 

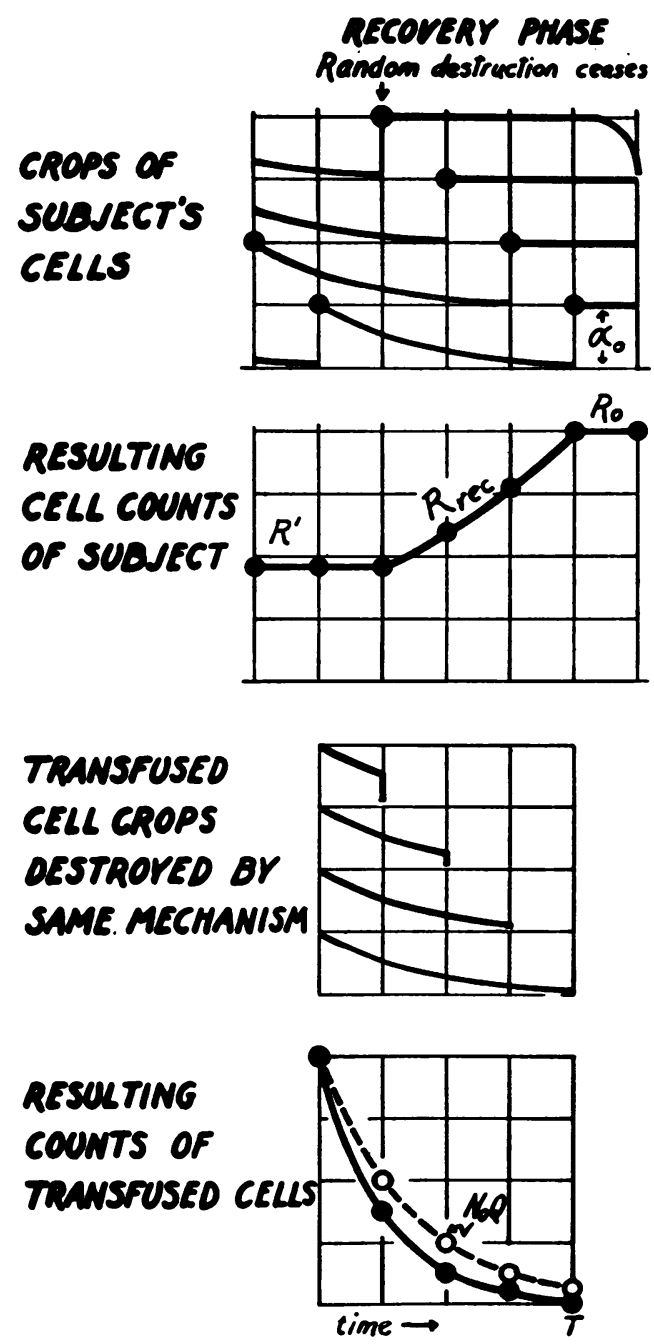

Fig. 9. Relation of the Disappearance Curve of Transfused Normal Erythrocytes to the Increasing Cell Counts of the Subject during the Recovery Phase of Random Destruction

Under the specific assumption made in this example the crops of the subject's cells, pre-existing when the damaging mechanism ceases, continue to be lost in random fashion, whereas new crops survive normally. During this phase the sums of both new and pre-existing crops form a curve $R_{r o e}$ which is the expected erythrocyte count of the patient, provided that the rate of cell release is normal throughout. The NoQ curve of normal cells, transfused just before cessation of the destructive mechanism, can be made congruent with the disappearance curve of a single crop of "pre-existing" cells. But the values on this curve plus the baseline $R^{\prime}$ are still less than the values for $R_{\text {roc }}$ because the latter is enhanced by the addition of the cells of the "new" crops which survive normally. tions of the experiment, indicate that the data are derived during the induction phase. The previous assumptions are made that the biologically tagged cells are destroyed in the same manner as those of the subject and the potential life spans of the two populations are approximately the same.

The $N_{0} Q$ values for the observed inagglutinable cell counts are computed from equation 4 and plotted on the vertical axis of Cartesian coordinates against time in days after the beginning of the induction phase on the horizontal axis. A smoothed curve is drawn through the points and an enclosing rectangle is constructed, as in Figure 8, with its base the horizontal axis from $O$ to $T$, the vertical axis from $\mathrm{O}$ to $\mathrm{N}_{0}$ as the left side, a vertical line at $\mathrm{T}$ as the right side, and a horizontal line intersecting the vertical axis at $\mathrm{N}_{0}$ as the top. As in the steady state of random destruction, $\mathrm{N}_{0}$ (the count of inagglutinable cells immediately after transfusion) is determined by the intersection of the $N_{0} Q$ curve with the vertical axis. $T$ is usually taken at 120 days.

Values for $t$ are selected on the $N_{0} Q$ curve and the construction indicated in Figure 8 is made for each point. The area for $Z$ is measured by running a planimeter around the figure containing the sparse and dense stippling. The area of the rectangle can be measured with the planimeter or estimated from counting squares on the graph paper. The values for $R_{\text {ind }}$ are computed using equation 22. $R_{0}$ is usualy taken as 5 millions per mm. ${ }^{8}$ The observed values for the subject's cell counts are then compared with the computed values for $R_{\text {ind }}$ and significant discrepancies indicate changes from the normal rate of cell release. The method is applicable regardless of the shape of the $\mathrm{N}_{0} Q$ curve.

\section{PHASE OF RECOVERY FROM RANDOM DESTRUCTION}

In Figure 1, when the destructive mechanism ceases to act, the level of the subject's erythrocytes rises from the steady state $R^{\prime}$ to the normal level $R_{0}$ in a transition curve labeled $R_{\text {rec. }}$ The special case has been assumed in which the cells of the crops initially exposed to the destructive agent are unaffected by the cessation of the destructive agent and continue to be lost in random fashion, whereas "new" cells survive in a normal manner.

It will be recalled that $\mathrm{R}^{\prime}$ was defined as the level 


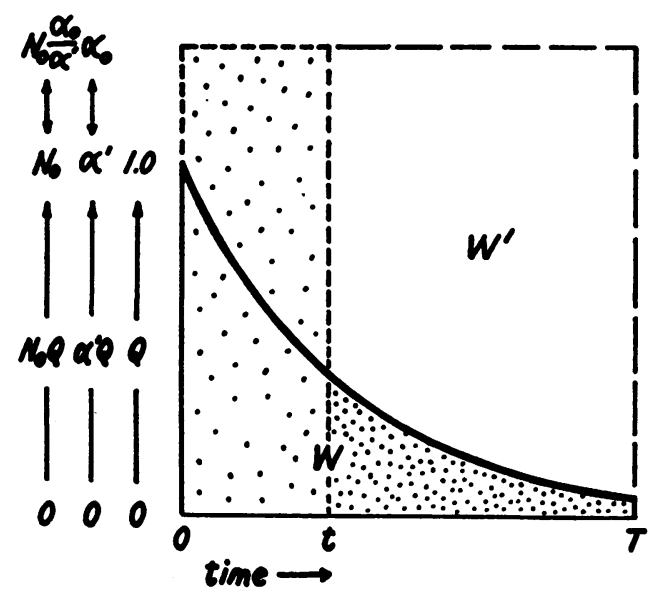

Fig. 10. Graphic Estimation of the Ascending Curve of Erythrocyte Counts in the Subject during the Recovery Phase from Random Destruction

The problem is to construct curve $R_{\text {roe }}$ in Figure 9 when $R_{0}$ is known, when the observed cell level during the steady state of random destruction has been measured in comparison with the expected level $R^{\prime}$, when the rate of cell release is normal during the recovery phase regardless of the rate during random destruction, and the manner of random destruction has been measured by the disappearance curve of transfused inagglutinable cell counts.

The N०Q values of the inagglutinable cell counts in the present figure are computed with equation 4 and plotted on the vertical axis of Cartesian coordinates against time after cessation of the destructive mechanism on the abscissa. $T$ is taken as the normal life span of erythrocytes, usually 120 days. The intersection of the ordinate by the curve determines $N_{0}$. A glance at $R_{\text {roc }}$ in Figure 9 will show that it will exhibit a different rate of climb if it begins at a level different than $R^{\prime}$, which is defined as the cell level expected in the steady state of random destruction when the rate of cell release is normal. If the cell release rate has been abnormal, the observed cell level will differ from $R^{\prime}$. The fraction $\frac{\alpha_{0}}{\alpha^{\prime}}=\frac{R^{\prime}}{\text { actual cell level }}$ is then computed for the steady state of random destruction, and is then employed to obtain the expression $\mathrm{N}_{0} \frac{\alpha^{\prime}}{\alpha_{0}}$. The value for the latter is plotted on the ordinate of the graph and the top of the rectangle is formed by a horizontal line through it. As in Figure 8, the densely stippled area represents the "pre-existing" cells and the sparsely stippled area the "new" cells. The entire stippled area is designated as $\mathrm{W}$ and the unstippled area of the rectangle is $W^{\prime}$. Then at any time $t$

$$
\frac{R_{r \infty}}{R_{0}}=\frac{W}{W+W^{\prime}} \text { or } R_{r e 0}=R_{0}\left(\frac{W}{W+W^{\prime}}\right) .
$$

The areas $W$ and $W^{\prime}$ may be measured with a planimeter. of the subject's cell counts resulting from random destruction of cell crops which are produced by a normal rate of cell release. This value is then compared with the observed cell counts of the subject to determine whether the cell release rate was in fact normal. The contour of the curve $R_{\text {rec }}$ depends on whether it starts at $R^{\prime}$ or the observed cell level, if there is a discrepancy between the two. In Figure 9 the construction is based on an example in which the actual cell level of the subject during the steady state of random destruction coincides with $R^{\prime}$. If the number of cells in the crops during the steady state of random destruction is $\alpha^{\prime}$ rather than $\alpha_{0}$, the actual cell level will not coincide with $R^{\prime}$. These crops, being damaged initially by the destructive mechanism, continue to be lost at random after cessation of the destructive factor. The new crops, however, are formed of normal numbers and survive normally. The sums of the numbers present in all crops at any time $t$ during the recovery phase determine the points on the curve $R_{r e c}$, where $t$ is measured from the beginning of the recovery phase.

The number of "new" cells present at time $t$ is $\alpha_{0} t$, which is the sparsely stippled rectangle in Figure 10. The "pre-existing" cells present at time $t$ have ages from $t$ to $T$. The number of cells in any one crop at time $t$ is different from the number in any other crop. As before, the addition of increments of staggered crops is equivalent to adding the cells present at successive time units in a single curve. In the recovery phase the number of "pre-existing" cells is the sum of the cells of all crops of ages between $t$ and $T$. If $t^{\prime \prime}$ is a time between $t$ and $T$, the size of a crop of age $t^{\prime \prime}$ is $\alpha^{\prime} Q\left(t^{\prime \prime}\right)$. Hence the number of the "pre-existing" cells is proportional to the densely stippled area in Figure 10 and the total number of all cells, both "pre-existing" and "new," is represented by the entire stippled area $W$. As before, $R_{0}$ (which equals $\alpha_{0} t$ ) is represented by the area $W+W^{\prime}$ so that

$$
\mathrm{R}_{\mathrm{rec}}=\mathrm{R}_{0}\left(\frac{\mathrm{W}}{\mathrm{W}+\mathrm{W}^{\prime}}\right) \text {. }
$$

In the symbolism of calculus,

$$
\begin{aligned}
R_{r e 0}(t) & =\alpha_{0} t+\alpha^{\prime} \int_{t}^{T} Q\left(t^{\prime \prime}\right) d^{\prime \prime} \\
& =\alpha^{\prime}\left[\frac{\alpha_{0}}{\alpha^{\prime}} t+\int^{T} Q\left(t^{\prime \prime}\right) d t^{\prime \prime}\right] .
\end{aligned}
$$


From equations 17 and 29

$$
\frac{R_{\mathrm{rec}}(t)}{R_{0}}=\frac{\alpha^{\prime}\left[\frac{\alpha_{0}}{\alpha^{\prime}} t+\int_{t}^{T} Q\left(t^{\prime \prime}\right) d t^{\prime \prime}\right]}{\alpha_{0} T} .
$$

Multiplying numerator and denominator by $\mathrm{N}_{\circ} / \boldsymbol{\alpha}^{\prime}$

$$
\begin{gathered}
\frac{R_{\text {reo }}(t)}{R_{0}}=\frac{\frac{\alpha_{0}}{\alpha^{\prime}} N_{0} t+\int_{t}^{T} N_{0} Q\left(t^{\prime \prime}\right) d t^{\prime \prime}}{\frac{\alpha_{0}}{\alpha^{\prime}} N_{0} T} \\
R_{\text {reo }}(t)=R_{0}\left(\frac{W}{W+W^{\prime}}\right) .
\end{gathered}
$$

\section{Graphic Method for Estimating the Rate of Cell Release}

The problem is to estimate the expected erythrocyte counts of the subject during the recovery phase from random destruction when the rate of that destruction has been indicated by a series of inagglutinable cell counts. In this case the data must be secured from a tagged-cell transfusion given before the onset of the recovery phase.

The $N_{\circ} Q$ values for the inagglutinable cell counts are calculated with equation 4 and plotted on the vertical axis of Cartesian coordinates against time after the beginning of the recovery phase in days on the abscissa. A smoothed curve is drawn through the points. The graph is enclosed in a rectangle similar to that in Figure 10, using the horizontal axis from $\mathrm{O}$ to $\mathrm{T}$ (usually 120 days) for the base, the vertical axis of the graph as the left side, and a vertical line at $T$ for the right side.

The horizontal line forming the top of the rectangle is constructed at a height $\mathrm{N}_{0} \cdot \frac{\alpha_{0}}{\alpha^{\prime}}$ on the vertical scale of the graph. $\mathrm{N}_{0}$ is determined by the intersection of the $N_{0} Q$ curve with the vertical axis. The fraction is computed from equation 21 . For each value selected for $t$ on the $N_{0} Q$ curve the construction indicated in Figure 10 is made, the entire stippled area is then measured with a planimeter, obtaining the area $W$. The area of the rectangle $W+W^{\prime}$ may be measured with the planimeter or estimated by counting squares on the graph paper. Each point for $\mathrm{R}_{\mathrm{rec}}$ is then computed using equation 28 .

The curve produced by the points calculated for
$R_{\text {rec }}$ represents the expected erythrocyte counts of the subject during the recovery phase from random destruction, when the rate of cell release during recovery is normal, when the subject's cells have been randomly destroyed in the same manner as the tagged cells, when the cells of crops initially damaged by the destructive mechanism continue to be lost at random unaltered by the cessation of the destructive mechanism, and when the potential life spans of the subject's and donor's cells are approximately equal. Comparison of the observed values for the subject's cell counts with the $R_{\text {rec }}$ curve reveals whether the rate of erythrocyte release was normal, accelerated, or diminished. This method is applicable regardless of the shape of the $N_{0} Q$ curve.

\section{SUM MARY}

Employing simultaneous counts of the subject's erythrocytes and the inagglutinable cell counts from fresh normal transfused blood of heterologous blood group, graphic methods have been presented by which, with appropriate assumptions, the following can be estimated in the human subject: (a) The rate of random destruction of transfused erythrocytes; $(b)$ the rate of numerical release of erythrocytes to the circulation of the subject during an apparently normal steady state; $(c)$ the rate of cell release in the subject during a steady state in which release of cells attains an equilibrium with a constant process of random destruction plus loss by normal aging; $(d)$ the rate of cell release in a subject from the inception of a random destructive mechanism until a steady state is attained; $(e)$ the rate of cell release in a subject during recovery from a period of random destruction of cells.

An explanation is offered for the constantly low erythrocyte counts observed in some cases of hemolytic anemia.

\section{REFERENCES}

1. DeGowin, E. L., Sheets, R. F., and Hamilton, H. E., Studies with inagglutinable erythrocyte counts. I. A method for measurement of net gain or deficit of red cells in the human subject. J. Clin. Invest., 1950, 29, 693.

2. Sheets, R. F., Janney, C. D., Hamilton, H. E., and DeGowin, E. L., Studies with inagglutinable eryth- 
rocyte counts. III. Kinetics of ertyhrocyte detruction in human beings. J. Clin. Invest., 1951, 30, 1272.

3. Callender, S. T., Powell, E. O., and Witts, L. J., The life-span of the red cell in man. J. Path. \& Bact., 1945, 57, 129.

4. Shemin, D., and Rittenberg, D., The life span of the human red blood cell. J. Biol. Chem., 1946, 166, 627.
5. Dornhorst, A. C., The interpretation of red cell survival curves. Blood, 1951, 6, 1284.

6. London, I. M., Shemin, D., West, R., and Rittenberg, D., Heme synthesis and red blood cell dynamics in normal humans and in subjects with polycythemia vera, sickle-cell anemia, and pernicious anemia. J. Biol. Chem., 1949, 179, 463.

7. Berlin, N. I., Lawrence, J. H., and Lee, H. C., The life span of the red blood cell in chronic leukemia and polycythemia. Science, 1951, 114, 385. 